\title{
Both resistance- and endurance-type exercise reduce the prevalence of hyperglycaemia in individuals with impaired glucose tolerance and in insulin-treated and non-insulin-treated type 2 diabetic patients
}

\author{
J.-W. van Dijk • R. J. F. Manders • K. Tummers • \\ A. G. Bonomi • C. D. A. Stehouwer • F. Hartgens • \\ L. J. C. van Loon
}

Received: 15 August 2011 / Accepted: 26 October 2011 /Published online: 29 November 2011

(C) The Author(s) 2011. This article is published with open access at Springerlink.com

\begin{abstract}
Aims/hypothesis The present study compares the impact of endurance- vs resistance-type exercise on subsequent $24 \mathrm{~h}$ blood glucose homeostasis in individuals with impaired glucose tolerance (IGT) and type 2 diabetes.

Methods Fifteen individuals with IGT, 15 type 2 diabetic patients treated with exogenous insulin (INS), and 15 type 2 diabetic patients treated with oral glucose-lowering medication (OGLM) participated in a randomised crossover experiment. Participants were studied on three occasions for 3 days under strict dietary standardisation, but otherwise free-living conditions. Blood glucose homeostasis was
\end{abstract}

J.-W. van Dijk • R. J. F. Manders · K. Tummers •

L. J. C. van Loon $(\square)$

Department of Human Movement Sciences,

NUTRIM School for Nutrition, Toxicology and Metabolism,

Maastricht University Medical Centre+,

PO Box 616, 6200 MD Maastricht, the Netherlands

e-mail: L.vanloon@maastrichtuniversity.nl

\section{A. G. Bonomi}

Department of Human Biology, NUTRIM School

for Nutrition, Toxicology and Metabolism,

Maastricht University Medical Centre+,

Maastricht, the Netherlands

\section{D. A. Stehouwer}

Department of Internal Medicine, CARIM

Cardiovascular Research Institute Maastricht,

Maastricht University Medical Centre+,

Maastricht, the Netherlands

\section{F. Hartgens}

Departments of Epidemiology and Surgery, Research

School CAPHRI, Maastricht University Medical Centre+,

Maastricht, the Netherlands assessed by ambulatory continuous glucose monitoring over the $24 \mathrm{~h}$ period following a $45 \mathrm{~min}$ session of resistance-type exercise ( $75 \%$ one repetition maximum), endurance-type exercise (50\% maximum workload capacity) or no exercise at all.

Results Average $24 \mathrm{~h}$ blood glucose concentrations were reduced from $7.4 \pm 0.2,9.6 \pm 0.5$ and $9.2 \pm 0.7 \mathrm{mmol} / \mathrm{l}$ during the control experiment to $6.9 \pm 0.2,8.6 \pm 0.4$ and $8.1 \pm 0.5$ $\mathrm{mmol} / \mathrm{l}$ (resistance-type exercise) and $6.8 \pm 0.2,8.6 \pm 0.5$ and $8.5 \pm 0.5 \mathrm{mmol} / 1$ (endurance-type exercise) over the $24 \mathrm{~h}$ period following a single bout of exercise in the IGT, OGLM and INS groups, respectively $(p<0.001$ for both treatments). The prevalence of hyperglycaemia (blood glucose $>10 \mathrm{mmol} / \mathrm{l}$ ) was reduced by $35 \pm 7$ and $33 \pm 11 \%$ over the $24 \mathrm{~h}$ period following a single session of resistanceand endurance-type exercise, respectively $(p<0.001$ for both treatments).

Conclusions/interpretation A single session of resistanceor endurance-type exercise substantially reduces the prevalence of hyperglycaemia during the subsequent $24 \mathrm{~h}$ period in individuals with IGT, and in insulin-treated and non-insulin-treated type 2 diabetic patients. Both resistance- and endurance-type exercise can be integrated in exercise intervention programmes designed to improve glycaemic control.

Trial registration: Clinicaltrials.gov NCT00945165

Funding: The Netherlands Organization for Health Research and Development (ZonMw, the Netherlands).

Keywords Continuous glucose monitoring - Exercise . Glycaemic control · Postprandial hyperglycaemia .

Type 2 diabetes mellitus 


$\begin{array}{ll}\text { Abbreviations } \\ \text { ACSM } & \text { American College of Sports Medicine } \\ \text { IGT } & \text { Impaired glucose tolerance } \\ \text { INS } & \text { Exogenous insulin } \\ \text { OGIS } & \text { Oral glucose insulin sensitivity (index) } \\ \text { OGLM } & \text { Oral glucose-lowering medication } \\ \text { PAL } & \text { Physical activity level } \\ \text { 1RM } & \text { One repetition maximum } \\ W_{\max } & \text { Maximum workload capacity }\end{array}$

\section{Introduction}

Over the last 15 years, postprandial hyperglycaemia has been increasingly recognised as a strong and independent risk factor for the development of cardiovascular complications in type 2 diabetic patients [1]. Nevertheless, postprandial hyperglycaemia is highly prevalent throughout the day in type 2 diabetic patients, even in patients with apparently good glycaemic control according to their $\mathrm{HbA}_{1 \mathrm{c}}$ levels [2, 3]. Therefore, more effective treatment strategies should be defined to reduce the prevalence of postprandial hyperglycaemia.

Structured exercise programmes have been shown to improve long-term glycaemic control (i.e. $\mathrm{HbA}_{1 \mathrm{c}}$ ) in type 2 diabetic patients $[4,5]$. The glucoregulatory effects of exercise result from an increased insulin sensitivity, which has been shown to persist for up to $48 \mathrm{~h}$ following a single bout of exercise [6-8]. In accordance, we have recently shown that a single bout of exercise can strongly reduce the prevalence of hyperglycaemia throughout the day [9]. Consequently, the benefits of exercise on long-term glycaemic control can be largely ascribed to the cumulative glucoregulatory effects of each successive bout of exercise $[6,7]$. To optimise the impact of exercise as an effective strategy to improve glycaemic control, more information is needed on the impact of the various exercise modalities (e.g. type, intensity, duration, frequency and timing of exercise) on daily blood glucose homeostasis.

From a historical perspective, endurance exercise has always been the type of exercise implemented in diabetes intervention programmes. This is attributable to the successful application of endurance-type exercise training as a means to reduce fat mass and improve weight maintenance $[10,11]$. However, endurance-type exercise is not always the most applicable type of exercise as many type 2 diabetic patients suffer from muscle weakness, cardiovascular comorbidities, polyneuropathy and reduced exercise tolerance [12-14], which generally lower the feasibility of strict endurance-type exercise programmes. Furthermore, the loss of skeletal muscle mass, strength and function in the ageing diabetes population forms a major therapeutic target that requires the implementation of resistance-type exercise $[12,14,15]$. This has resulted in the inclusion of a statement in the current ADA/American College of Sports Medicine (ACSM) exercise guidelines for type 2 diabetic patients that in addition to aerobic training, persons with type 2 diabetes should undertake moderate to vigorous resistance training at least 2-3 days per week' [13]. However, this 2010 joint position statement also recognises that the impact of a single bout of resistancetype exercise on glycaemic control in type 2 diabetic patients remains to be established. As it is presently unclear whether resistance-type exercise can also modulate glycaemic control throughout the subsequent day, healthcare professionals have been rather restrictive in the implementation of resistancetype exercise in diabetes intervention programmes.

To provide support for the current recommendations concerning optimal exercise prescription in type 2 diabetes treatment, this study investigates the impact of both resistance- and endurance-type exercise on daily blood glucose homeostasis. Therefore, we assessed $24 \mathrm{~h}$ glycaemic control following a single bout of resistance- as well as endurance-type exercise in individuals with impaired glucose tolerance (IGT), type 2 diabetic patients treated with oral blood-glucose-lowering medication (OGLM), and type 2 diabetic patients treated with exogenous insulin (INS).

\section{Methods}

Participants Fifteen men with IGT and 30 men with type 2 diabetes were recruited to participate. All patients with type 2 diabetes had been treated with stable OGLM only $(n=15)$ or insulin $(n=15)$ for at least 3 months before being recruited. Exclusion criteria were renal failure, liver disease, morbid obesity (BMI $>40 \mathrm{~kg} / \mathrm{m}^{2}$ ), hypertension $(>160 \mathrm{mmHg}$ systolic and/or $>100 \mathrm{mmHg}$ diastolic), and a history of severe cardiovascular problems (myocardial infarction in the last year or stroke). All volunteers were informed about the nature and the risks of the experimental procedures before their written informed consent was obtained. The Medical Ethical Committee of the Maastricht University Medical Centre+ approved all clinical experiments.

Screening and pretesting All participants, except for the INS group, underwent an OGTT. In the OGLM group, blood-glucose-lowering medication was withheld 2 days prior to the OGTT. After an overnight fast, participants arrived at the laboratory at 08:00 hours by car or public transportation. A fasting blood sample was obtained, after which an OGTT was performed to determine IGT or type 2 diabetes according to ADA criteria [16]. Maximum strength (one repetition maximum [1RM]) was determined for the leg press and leg extension as described previously [17]. Participants performed an incremental cycling test to 
determine their maximum workload capacity $\left(W_{\max }\right)$. After a $2.5 \mathrm{~min}$ warm-up at $0.75 \mathrm{~W} / \mathrm{kg}$ body weight, workload was increased with $0.25 \mathrm{~W} / \mathrm{kg}$ body weight every $2 \mathrm{~min}$ until exhaustion. Cardiac function was monitored using a 12 lead electrocardiogram.

Blood sample analysis During the screening, venous blood samples $(10 \mathrm{ml})$ were collected in EDTA-containing tubes and centrifuged at $1,000 \mathrm{~g}$ and $4^{\circ} \mathrm{C}$ for $10 \mathrm{~min}$. Aliquots of plasma were immediately frozen in liquid nitrogen and stored at $-80^{\circ} \mathrm{C}$ until analyses. Glucose concentrations (Roche, Basel, Switzerland), NEFA concentrations (Wako Chemicals, Neuss, Germany), triacylglycerol concentrations (ABX Diagnostics, Montpellier, France) and total cholesterol concentrations (ABX Diagnostics) were determined enzymatically with the COBAS FARA semiautomatic analyzer (Roche). Plasma insulin concentrations were determined by radioimmunoassay (HI-14K, Linco Research, St Charles, MI, USA). $\mathrm{HbA}_{1 \mathrm{c}}$ content was determined in $3 \mathrm{ml}$ venous blood samples by highperformance liquid chromatography (Bio-Rad Diamat, Munich, Germany). Venous plasma glucose and insulin concentrations obtained during the OGTT were used to assess insulin sensitivity with the oral glucose insulin sensitivity (OGIS) index [18].

Study design All participants participated in a randomised crossover experiment, consisting of three intervention periods separated by at least 4 days. Each intervention period consisted of 3 days during which the impact of a single session of exercise on subsequent $24 \mathrm{~h}$ blood glucose homeostasis was assessed under standardised dietary, but otherwise free living, conditions (Fig. 1). Periods were identical with the exception of the type of exercise that was performed (no exercise, resistance- or endurance-type exercise). On day 1 of each intervention period, participants arrived at the laboratory in the afternoon and received a short training in the use of the capillary blood sampling method (Glucocard X Meter, Arkray, Kyoto, Japan). Subsequently, a continuous glucose monitoring device (GlucoDay S; A. Menarini Diagnostics, Florence, Italy) was attached, after which participants returned home. On day 2, participants arrived at the laboratory at 08:30 hours for breakfast. After a resting period, the exercise or control intervention was performed from 11:00 to 11.45 hours. After lunch at 12:30 hours, participants were free to go home and resume their normal daily activities. On day 3 , participants arrived at the laboratory in the afternoon for removal of the continuous-glucose-monitoring device.

Exercise protocol The endurance-type exercise session consisted of $45 \mathrm{~min}$ of continuous cycling, performed on a cycle ergometer (Lode Excalibur, Groningen, the Netherlands). Based on earlier work [9], continuous cycling was performed at a moderate workload intensity $\left(50 \% W_{\max }\right)$. The $45 \mathrm{~min}$ resistance-type exercise session started with two upper-body resistance exercise machines (lateral pull down and chest press). A warming-up set was performed at a workload of $20 \%$ bodyweight, followed by three sets of ten repetitions at $40 \%$ bodyweight. Thereafter, the resistance exercise session targeted the legs (i.e. leg press, leg extension). Based on earlier reports [17, 19], five sets of ten repetitions were performed at $55 \%, 65 \%, 75 \%$, $75 \%$ and $75 \%$ of the participants' individual $1 \mathrm{RM}$, respectively. A resting period of approximately 2 min was allowed between sets. During the control (no exercise) experiment participants were seated for $45 \mathrm{~min}$ in a chair next to the cycle ergometer.

Diet and physical activity All participants were asked to maintain habitual physical activity patterns throughout the experimental period, but to refrain from exhaustive physical

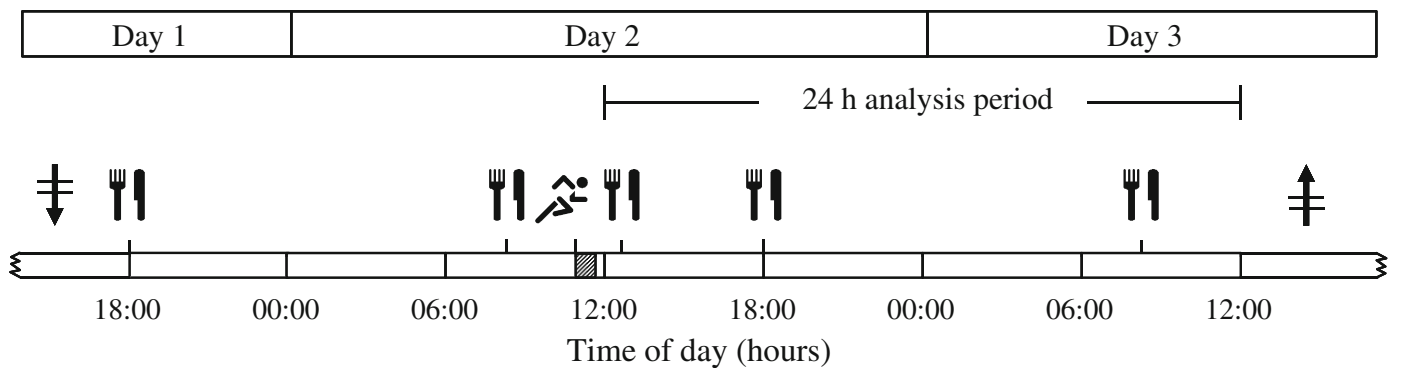

Fig. 1 Schematic overview of an experimental period. On day 1, participants reported to the laboratory in the afternoon for insertion of the continuous-glucose-monitoring device (downward arrow with horizontal lines), after which they were free to go home and resume their normal daily activities. During an experimental period, participants consumed a strictly standardised diet with main meals (knife and fork) at 08:30, 12:30 and 18:00 hours. On day 2, participants arrived at the laboratory at 08:30 hours for breakfast. After a resting period, the resistance-type exercise, endurance-type exercise or control (no exercise) intervention (running symbol) was performed from 11:00 to 11:45 hours. After lunch, participants were free to go home and resume their normal daily activities. On day 3 , participants arrived at the laboratory in the afternoon for removal of the continuous-glucose-monitoring device (upward arrow with horizontal lines). The glycaemic profiles obtained during the $24 \mathrm{~h}$ period following exercise (from 12:00 to 12:00 hours) were used for analysis 
labour and exercise training for 2 days prior to and during the intervention period. During the intervention period, habitual physical activity was assessed using a validated triaxial accelerometer (Philips DirectLife, Eindhoven, the Netherlands) [20], worn in a belt around the waist. Accelerometer data obtained during the $24 \mathrm{~h}$ period following exercise were used to calculate physical activity level (PAL) applying the equation by Bonomi et al. [20].

During each intervention period, participants were provided with a healthy standardised diet, composed according to the ADA dietary recommendations for type 2 diabetes [21]. The diet consisted of three meals and three snacks per day, distributed in pre-weighed packages and ingested at pre-determined time-points to ensure a fully standardised diet during the $\sim 48 \mathrm{~h}$ test periods. The diet provided $10.4 \pm 0.1 \mathrm{MJ} /$ day consisting of $57 \%$ of energy from carbohydrate, $13 \%$ of energy from protein and 30\% of energy from fat. The diet was designed to meet the energy requirements as calculated with the Harris-Benedict equation (1918) multiplied by a PAL of 1.4 .

Medication Patients' blood-glucose-lowering medications are shown in Table 1. Treatment with OGLM and/or insulin was continued as normal throughout the entire experimental period. Insulin-treated diabetic patients were explicitly asked not to deviate from their habitual insulin treatment schemes when exercise was performed. None of the volunteers in the IGT group was using any medication known to interfere with glucose metabolism.

Statistics and data analysis The acquired data from the continuous glucose monitor were downloaded to a personal computer with GlucoDay software (V3.2.2). Values reported by the continuous-glucose-monitoring device were converted into glucose values using the self-monitored capillary blood glucose values. The glycaemic profiles during the $24 \mathrm{~h}$ period following exercise (from 12:00 to 12:00 hours) were used to determine average glucose concentrations, the prevalence of hyperglycaemia (glucose concentrations $>10 \mathrm{mmol} / \mathrm{l}$ ), and the prevalence of hypoglycaemia (glucose concentrations $<3.9 \mathrm{mmol} / \mathrm{l}$ ). In addition, these variables were also calculated over four different periods within the $24 \mathrm{~h}$ time frame: the afternoon (12:00-18:00 hours), evening (18:00-00:00 hours), nocturnal (00:00-06:00 hours) and morning (06:00-12:00 hours) periods.

Intervention effects were assessed by one-way repeated measures ANOVA, with intervention, group and intervention $\times$ group as within-subject factor, between-subject factor and interaction, respectively. When applicable, pairwise comparisons with Bonferroni correction were applied to locate differences between interventions, and Scheffe's post hoc test was applied to locate differences between groups. Statistical comparisons were considered significant when $p$ values were $<0.05$. All statistical calculations were performed using the SPSS 15.0.1.1 software package. Unless otherwise specified, reported results represent means \pm SEM.

\section{Results}

Participants Participants' characteristics are shown in Table 1. Groups were comparable with respect to age and BMI. Type 2 diabetic patients in the OGLM group had been diagnosed with diabetes for $6.5 \pm 1.0$ years, whereas patients in the INS group had been diagnosed for $13.5 \pm 2.2$ years $(p<0.05)$ and had been treated with insulin for $5.1 \pm 1.2$ years. $\mathrm{HbA}_{1 \mathrm{c}}$ content was similar in the OGLM and INS groups ( $7.5 \pm 0.2$ and $7.6 \pm 0.3 \%$, respectively), but lower in the IGT group $(6.1 \pm 0.1 \% ; p<0.05)$. Fasting plasma glucose concentrations were similar in the OGLM and INS groups $(9.8 \pm 0.6$ and $8.4 \pm 0.6 \mathrm{mmol} / \mathrm{l}$, respectively), but lower in the IGT group $(6.3 \pm 0.2 \mathrm{mmol} / \mathrm{l} ; p<0.05)$. Fasting plasma insulin concentrations tended to be higher in the IGT group $(174 \pm 24 \mathrm{pmol} / \mathrm{l})$ when compared with the OGLM group $(114 \pm 17 \mathrm{pmol} / \mathrm{l} ; p=0.053)$, and $2 \mathrm{~h}$ postchallenge plasma insulin concentrations were threefold higher in the IGT group $(893 \pm 179 \mathrm{pmol} / \mathrm{l})$ compared with the OGLM group $(278 \pm 55 \mathrm{pmol} / \mathrm{l} ; p<0.05)$. No significant differences were observed in the OGIS index between the IGT and OGLM groups $(289 \pm 18$ and $296 \pm 17$

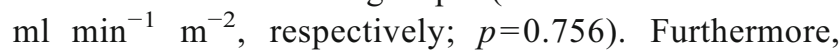
no differences in exercise performance (1RM and $W_{\max }$ ) were observed when comparing the subpopulations included.

Experimental periods All 45 participants successfully completed each of the three experimental treatments (resistance-type exercise, endurance-type exercise and no exercise). Participants were compliant with respect to their medication and standardised diet, as verified by dietary records. Both dosing and timing of blood-glucose-lowering medication were identical during the three experimental periods, since these factors were registered during the first experimental period and replicated during second and third period. During the experimental periods, insulintreated type 2 diabetic patients were using $0.66 \pm 0.07 \mathrm{U}$ insulin ( $\mathrm{kg}$ body weight $)^{-1}$ day $^{-1}$.

Habitual physical activity Overall, habitual PALs over the $24 \mathrm{~h}$ following a single session of both resistance- and endurance-type exercise (PAL $1.69 \pm 0.13$ and $1.69 \pm 0.12$ ) did not differ from the control experiment $(1.69 \pm 0.13$; $p=0.989$ ). No differences in PAL were observed between groups (between-group effect $p=0.389$ ).

$24 \mathrm{~h}$ glucose concentrations During the control experiment, average $24 \mathrm{~h}$ blood glucose concentrations were $7.4 \pm 0.2$, 
Table 1 Participants' characteristics

\begin{tabular}{|c|c|c|c|c|}
\hline \multirow[b]{2}{*}{ Characteristic } & \multicolumn{3}{|l|}{ Group } & \multirow[b]{2}{*}{$p$ value } \\
\hline & IGT $(n=15)$ & OGLM $(n=15)$ & INS $(n=15)$ & \\
\hline Age (years) & $61 \pm 2$ & $60 \pm 1$ & $61 \pm 1$ & 0.860 \\
\hline Time since diagnosis of type 2 diabetes (years) & NA & $6.5 \pm 1.0$ & $13.5 \pm 2.2^{*}$ & 0.008 \\
\hline Time on insulin therapy (years) & NA & NA & $5.1 \pm 1.2$ & NA \\
\hline BMI $\left(\mathrm{kg} / \mathrm{m}^{2}\right)$ & $31.7 \pm 1.1$ & $29.7 \pm 0.8$ & $29.7 \pm 1.1$ & 0.210 \\
\hline $\mathrm{HbA}_{1 \mathrm{c}}(\%)$ & $6.1 \pm 0.1$ & $7.5 \pm 0.2^{\dagger}$ & $7.6 \pm 0.3^{\dagger}$ & $<0.001$ \\
\hline $\mathrm{HbA}_{1 \mathrm{c}}(\mathrm{mmol} / \mathrm{mol})$ & $43 \pm 1$ & $58 \pm 3^{\dagger}$ & $60 \pm 3^{\dagger}$ & $<0.001$ \\
\hline Fasting plasma glucose (mmol/l) & $6.3 \pm 0.2$ & $9.8 \pm 0.6^{\dagger}$ & $8.4 \pm 0.6^{\dagger}$ & $<0.001$ \\
\hline $2 \mathrm{~h}$ post-challenge plasma glucose $(\mathrm{mmol} / \mathrm{l})$ & $9.2 \pm 0.2$ & $16.7 \pm 1.1^{\dagger}$ & NA & $<0.001$ \\
\hline Fasting plasma insulin (pmol/1) & $174 \pm 24$ & $114 \pm 17$ & NA & 0.053 \\
\hline $2 \mathrm{~h}$ post-challenge plasma insulin (pmol/1) & $893 \pm 179$ & $278 \pm 55^{\dagger}$ & NA & $<0.001$ \\
\hline OGIS index $\left(\mathrm{ml} \mathrm{min}{ }^{-1} \mathrm{~m}^{-2}\right)$ & $289 \pm 18$ & $296 \pm 17$ & NA & 0.756 \\
\hline Total cholesterol $(\mathrm{mmol} / \mathrm{l})$ & $5.41 \pm 0.29$ & $4.94 \pm 0.23$ & $4.35 \pm 0.21^{\dagger}$ & 0.009 \\
\hline Fasting plasma TG (mmol/l) & $2.00 \pm 0.24$ & $1.61 \pm 0.20$ & $1.58 \pm 0.20$ & 0.275 \\
\hline Fasting plasma NEFA $(\mu \mathrm{mol} / \mathrm{l})$ & $605 \pm 56$ & $573 \pm 62$ & $471 \pm 47$ & 0.154 \\
\hline Systolic blood pressure (mmHg) & $140 \pm 5$ & $140 \pm 4$ & $139 \pm 3$ & 0.994 \\
\hline Diastolic blood pressure (mmHg) & $78 \pm 3$ & $80 \pm 1$ & $78 \pm 2$ & 0.817 \\
\hline$W_{\max }(\mathrm{W} / \mathrm{kg}$ body weight $)$ & $2.1 \pm 0.2$ & $1.9 \pm 0.1$ & $1.8 \pm 0.1$ & 0.229 \\
\hline Leg press 1RM (kg) & $200 \pm 10$ & $199 \pm 8$ & $209 \pm 12$ & 0.347 \\
\hline Leg extension 1RM (kg) & $86 \pm 4$ & $97 \pm 4$ & $85 \pm 6$ & 0.174 \\
\hline OGLM $(n)$ & 0 & 15 & 10 & NA \\
\hline Metformin + SUD and/or TZD $(n)$ & 0 & 6 & 1 & NA \\
\hline Metformin only $(n)$ & 0 & 8 & 8 & NA \\
\hline SUD only $(n)$ & 0 & 1 & 0 & NA \\
\hline TZD only $(n)$ & 0 & 0 & 1 & NA \\
\hline Insulin treatment $(n)$ & 0 & 0 & 15 & NA \\
\hline Basal $(n)$ & 0 & 0 & 2 & NA \\
\hline Biphasic $(n)$ & 0 & 0 & 4 & NA \\
\hline Multiple (n) & 0 & 0 & 7 & NA \\
\hline Pump $(n)$ & 0 & 0 & 2 & NA \\
\hline Insulin dose $\left(\mathrm{U}[\mathrm{kg} \text { body weight }]^{-1} \mathrm{day}^{-1}\right)$ & 0 & 0 & $0.66 \pm 0.07$ & NA \\
\hline
\end{tabular}

Data are expressed as means \pm SEM or frequencies

In the OGLM group, glucose, insulin, and OGIS index were determined from an OGTT, performed after 2 days of discontinuation of habitual use of OGLM Significantly different when compared with the OGLM group $\left({ }^{*} p<0.05\right)$; significantly different when compared with the IGT group $\left({ }^{\dagger} p<0.05\right)$ NA, not applicable; SUD, sulfonylurea; TG, triacylglycerol; TZD, thiazolidinedione

$9.6 \pm 0.5$ and $9.2 \pm 0.7 \mathrm{mmol} / \mathrm{l}$ in the IGT, OGLM and INS groups, respectively (Fig. 2a). Over the $24 \mathrm{~h}$ following a single bout of resistance-type exercise, average blood glucose concentrations were lowered to $6.9 \pm 0.2,8.6 \pm 0.4$ and $8.1 \pm 0.5 \mathrm{mmol} / 1$ in the IGT, OGLM and INS groups, respectively $(p<0.001)$. Comparable effects were observed over the $24 \mathrm{~h}$ following endurance-type exercise, with average $24 \mathrm{~h}$ blood glucose concentrations being lowered to $6.8 \pm 0.2, \quad 8.6 \pm 0.5$ and $8.5 \pm 0.5 \mathrm{mmol} / 1$, respectively $(p<0.001)$. No differences were observed between the blood-glucose-lowering properties of resistance- and endurance-type exercise $(p=1.00)$. There was no exercise $\times$ group interaction $(p=0.473)$, indicating a similar effectiveness of both types of exercise in all subgroups. Independent of exercise treatments, a between-group effect was observed for average $24 \mathrm{~h}$ blood glucose concentrations $(p=0.016)$, indicating lower glucose concentrations in the IGT group when compared with both diabetic groups (Fig. 2a).

Prevalence of hyperglycaemia Despite the continued use of glucose-lowering medication and consumption of a healthy diet, participants experienced excessive hyperglycaemia throughout a considerable part of the day. In fact, hyperglycaemia was prevalent for as much as 2:11 $\pm 0: 37,9: 01 \pm 1: 39$ 

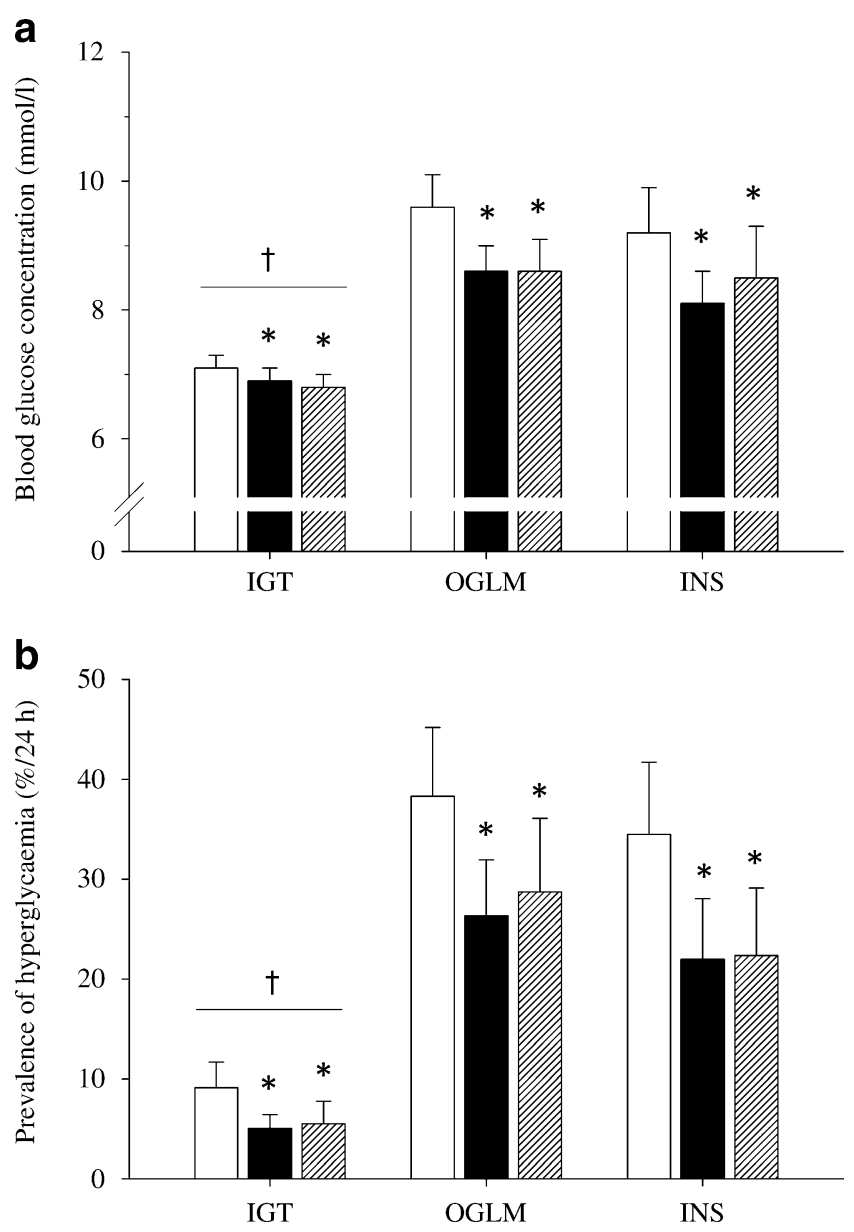

Fig. 2 Average glucose concentrations (a) and the prevalence of hyperglycaemia (glucose concentrations $>10 \mathrm{mmol} / \mathrm{l}$ ) (b) in individuals with IGT, type 2 diabetic patients using OGLM only, and type 2 diabetic patients using insulin, assessed over the $24 \mathrm{~h}$ following no exercise (control; white bars), resistance-type exercise (black bars) and endurance-type exercise (hatched bars). Significantly different compared with the control experiment $\left({ }^{*} p<0.05\right)$; significant group effect compared with OGLM and INS groups $\left({ }^{\dagger} p<0.05\right)$

and 8:16 $\pm 1: 44 \mathrm{~h}: \min$ (over $24 \mathrm{~h}$ ) in the IGT, OGLM and INS groups, respectively. Over the $24 \mathrm{~h}$ following a single session of resistance-type exercise, the prevalence of hyperglycaemia was reduced to $1: 13 \pm 0: 20,6: 32 \pm 1: 21$ and 5:16 $\pm 1: 27 \mathrm{~h}: \mathrm{min}$ in the IGT, OGLM and INS groups, respectively. In a similar fashion, the prevalence of hyperglycaemia was decreased over the $24 \mathrm{~h}$ period following endurance-type exercise to 1:19 $\pm 0: 33,6: 53 \pm 1: 46$ and 5:21 $\pm 1: 37 \mathrm{~h}: \mathrm{min}$ in the IGT, OGLM and INS groups, respectively (Fig. 2b). As such, the prevalence of hyperglycaemia was reduced by $35 \pm 7 \%$ and $33 \pm 11 \%$ over the $24 \mathrm{~h}$ following a single session of resistance- and endurance-type exercise, respectively $(p<0.001$ for both exercise treatments). No differences were observed between the effects of both types of exercise on hyperglycaemia $(p=1.00)$. The effects of resistance- and endurance-type exercise on hyperglycaemia were similar in the subpopulations studied (exercise $\times$ group interaction $p=0.169$ ). Independent of exercise treatment, a betweengroup effect was observed $(p=0.005)$, indicating a shorter duration of hyperglycaemic episodes in the IGT group when compared with both diabetic groups (Fig. 2b).

Prevalence of hypoglycaemia During the control experiment, the average duration of hypoglycaemia was $0: 13 \pm 0: 05$, $0: 08 \pm 0: 05$, and $0: 39 \pm 0: 22 \mathrm{~h}: \mathrm{min}$ per day in the IGT, OGLM and INS groups, respectively. The prevalence of hypoglycaemia was comparable over the $24 \mathrm{~h}$ following resistance-type exercise $(0: 09 \pm 0: 05,0: 12 \pm 0: 10$ and $0: 30 \pm 0: 13 \mathrm{~h}: \mathrm{min})$ and endurance-type exercise $(0: 19 \pm 0: 08$, $0: 24 \pm 0: 13$ and $0: 35 \mathrm{~h}: \mathrm{min}$ ) in the IGT, OGLM and INS groups, respectively. As such, the prevalence of hypoglycaemia was not affected by exercise (main effect $p=0.602$ ). The effects of resistance- and endurance-type exercise on hypoglycaemia did not differ between the studied subpopulations (exercise $\times$ group interaction $p=0.926$ ). Independent of exercise treatment, the prevalence of hypoglycaemia tended to be higher in the INS group when compared with the IGT and OGLM groups (between-group effect $p=0.062$ ).

Glycaemic profile analysis Detailed data on the glucoselowering effects of exercise calculated over different time periods within the $24 \mathrm{~h}$ period are provided in Table 2 . Endurance-type exercise induced strong glucoregulatory effects over the first $6 \mathrm{~h}$ following exercise, as both average glucose levels and the prevalence of hyperglycaemia were lower during this time period when compared with the control experiment (Table 2). These glucoregulatory effects of a single bout of endurance-type exercise were also observed over the subsequent evening period (6-12 $\mathrm{h}$ later), and the following morning period (18-24 $\mathrm{h}$ later; Table 2). Over the subsequent afternoon and evening following a single bout of resistance-type exercise, the prevalence of hyperglycaemia tended to be lower when compared with the control experiment, but these observations did not reach statistical significance $(p<0.08)$. Interestingly, in the resistance-type exercise experiment, average glucose concentrations and the prevalence of hyperglycaemia were significantly reduced during the subsequent nocturnal and morning periods $(12-18 \mathrm{~h}$ later and $18-24 \mathrm{~h}$ later, respectively) following exercise (Table 2). Although none of the participants reported symptomatic hypoglycaemia during or directly after exercise, endurance-type exercise induced a slight increase in the prevalence of hypoglycaemia (blood glucose concentration $<3.9 \mathrm{mmol} / \mathrm{l}$ ) during this time period (11:00-12:30 hours; Table 2). 
Table 2 Glycaemic variables calculated over five different time frames during or after exercise in the control (no exercise), resistance-type exercise and endurance-type exercise experiment

\begin{tabular}{|c|c|c|c|c|c|c|}
\hline \multirow[t]{2}{*}{ Time frame/variables } & \multirow[t]{2}{*}{ Control } & \multirow[t]{2}{*}{ Resistance } & \multirow[t]{2}{*}{ Endurance } & \multicolumn{3}{|l|}{$p$ value } \\
\hline & & & & Exercise effect & Group effect & Exercis \\
\hline \multicolumn{7}{|l|}{$\begin{array}{l}\text { Exercise and immediately following exercise } \\
(11: 00-12: 30 \text { hours })\end{array}$} \\
\hline Average glucose concentration (mmol/l) & & & & 0.173 & $<0.001^{\S \text {, }}$ & 0.427 \\
\hline IGT & $7.1 \pm 0.3$ & $6.9 \pm 0.4$ & $7.0 \pm 0.4$ & & & \\
\hline OGLM & $11.7 \pm 1.0$ & $11.1 \pm 0.9$ & $9.8 \pm 0.8$ & & & \\
\hline INS & $10.8 \pm 0.9$ & $10.9 \pm 0.9$ & $10.4 \pm 1.1$ & & & \\
\hline Hyperglycaemia (h:min) & & & & 0.074 & $<0.001^{\S \text {, }}$ & 0.087 \\
\hline IGT & $0: 03 \pm 0: 02$ & $0: 05 \pm 0: 03$ & $0: 09 \pm 0: 04$ & & & \\
\hline OGLM & $0: 51 \pm 0: 09$ & $0: 47 \pm 0: 08$ & $0: 37 \pm 0: 08$ & & & \\
\hline INS & $0: 52 \pm 0: 09$ & $0: 49 \pm 0: 08$ & $0: 36 \pm 0: 07$ & & & \\
\hline Hypoglycaemia (h:min) & & & & 0.036 & 0.240 & 0.246 \\
\hline IGT & $0: 00 \pm 0: 00$ & $0: 04 \pm 0: 03$ & $0: 07 \pm 0: 04$ & & & \\
\hline OGLM & $0: 00 \pm 0: 00$ & $0: 00 \pm 0: 00$ & $0: 03 \pm 0: 02$ & & & \\
\hline INS & $0: 00 \pm 0: 00$ & $0: 00 \pm 0: 01$ & $0: 00 \pm 0: 00$ & & & \\
\hline \multicolumn{7}{|l|}{ Afternoon period (12:00-18:00 hours) } \\
\hline Average glucose concentration (mmol/l) & & & & $<0.001^{\dagger}$ & $0.003^{\S, \oplus}$ & 0.182 \\
\hline IGT & $6.7 \pm 0.3$ & $6.8 \pm 0.2$ & $6.5 \pm 0.3$ & & & \\
\hline OGLM & $9.9 \pm 0.8$ & $8.9 \pm 0.6$ & $8.1 \pm 0.7$ & & & \\
\hline INS & $9.6 \pm 0.8$ & $8.6 \pm 0.7$ & $8.0 \pm 0.4$ & & & \\
\hline Hyperglycaemia (h:min) & & & & $0.003^{\dagger}$ & $0.003^{\S, \pi}$ & 0.296 \\
\hline IGT & $0: 22 \pm 0: 10$ & $0: 11 \pm 0: 04$ & $0: 18 \pm 0: 14$ & & & \\
\hline OGLM & $2: 24 \pm 0: 31$ & $1: 51 \pm 0: 26$ & $1: 23 \pm 0: 32$ & & & \\
\hline INS & $2: 13 \pm 0: 13$ & $1: 38 \pm 0: 28$ & $1: 17 \pm 0: 18$ & & & \\
\hline Hypoglycaemia (h:min) & & & & 0.226 & 0.814 & 0.263 \\
\hline IGT & $0: 08 \pm 0: 05$ & $0: 06 \pm 0: 04$ & $0: 11 \pm 0: 05$ & & & \\
\hline OGLM & $0: 03 \pm 0: 03$ & $0: 02 \pm 0: 02$ & $0: 18 \pm 0: 12$ & & & \\
\hline INS & $0: 11 \pm 0: 06$ & $0: 03 \pm 0: 03$ & $0: 03 \pm 0: 02$ & & & \\
\hline \multicolumn{7}{|l|}{ Evening period (18:00-00:00 hours) } \\
\hline Average glucose concentration (mmol/l) & & & & $0.006^{*}, \dagger$ & $0.045^{\S}$ & 0.288 \\
\hline IGT & $7.8 \pm 0.5$ & $7.1 \pm 0.2$ & $7.1 \pm 0.4$ & & & \\
\hline OGLM & $9.2 \pm 0.4$ & $8.9 \pm 0.5$ & $9.1 \pm 0.6$ & & & \\
\hline INS & $9.2 \pm 0.8$ & $8.2 \pm 0.5$ & $7.7 \pm 0.7$ & & & \\
\hline Hyperglycaemia (h:min) & & & & $0.047^{\dagger}$ & $0.036^{\S}$ & 0.231 \\
\hline IGT & $0: 47 \pm 0: 21$ & $0: 25 \pm 0: 09$ & $0: 27 \pm 0: 15$ & & & \\
\hline OGLM & $2: 02 \pm 0: 26$ & $1: 48 \pm 0: 33$ & $2: 06 \pm 0: 36$ & & & \\
\hline INS & $2: 12 \pm 0: 36$ & $1: 25 \pm 0: 28$ & $0: 58 \pm 0: 27$ & & & \\
\hline Hypoglycaemia (h:min) & & & & $0.028^{\dagger, \grave{\ddagger}}$ & $0.014^{\boldsymbol{q}, * *}$ & 0.063 \\
\hline IGT & $0: 00 \pm 0: 00$ & $0: 00 \pm 0: 00$ & $0: 00 \pm 0: 00$ & & & \\
\hline OGLM & $0: 01 \pm 0: 01$ & $0: 00 \pm 0: 01$ & $0: 03 \pm 0: 02$ & & & \\
\hline INS & $0: 02 \pm 0: 01$ & $0: 02 \pm 0: 02$ & $0: 14 \pm 0: 06$ & & & \\
\hline \multicolumn{7}{|l|}{ Nocturnal period (00:00-06:00 hours) } \\
\hline Average glucose concentration (mmol/l) & & & & 0.124 & 0.126 & 0.301 \\
\hline IGT & $6.9 \pm 0.3$ & $6.6 \pm 0.2$ & $6.4 \pm 0.2$ & & & \\
\hline OGLM & $8.9 \pm 0.5$ & $8.3 \pm 0.6$ & $8.1 \pm 0.6$ & & & \\
\hline INS & $8.6 \pm 1.3$ & $7.3 \pm 0.6$ & $8.8 \pm 1.5$ & & & \\
\hline
\end{tabular}


Table 2 (continued)

\begin{tabular}{|c|c|c|c|c|c|c|}
\hline \multirow[t]{2}{*}{ Time frame/variables } & \multirow[t]{2}{*}{ Control } & \multirow[t]{2}{*}{ Resistance } & \multirow[t]{2}{*}{ Endurance } & \multicolumn{3}{|l|}{$p$ value } \\
\hline & & & & Exercise effect & Group effect & Exercise $\times$ group effect \\
\hline Hyperglycaemia (h:min) & & & & $0.016^{*}$ & 0.038 & 0.370 \\
\hline IGT & $0: 07 \pm 0: 03$ & $0: 03 \pm 0: 02$ & $0: 03 \pm 0: 03$ & & & \\
\hline OGLM & $1: 42 \pm 0: 30$ & $0: 57 \pm 0: 24$ & $1: 11 \pm 0: 29$ & & & \\
\hline INS & $1: 31 \pm 0: 35$ & $0: 49 \pm 0: 23$ & $1: 21 \pm 0: 39$ & & & \\
\hline Hypoglycaemia (h:min) & & & & 0.792 & 0.171 & 0.804 \\
\hline IGT & $0: 03 \pm 0: 03$ & $0: 07 \pm 0: 05$ & $0: 02 \pm 0: 01$ & & & \\
\hline OGLM & $0: 00 \pm 0: 00$ & $0: 02 \pm 0: 03$ & $0: 02 \pm 0: 01$ & & & \\
\hline INS & $0: 17 \pm 0: 16$ & $0: 11 \pm 0: 06$ & $0: 11 \pm 0: 05$ & & & \\
\hline \multicolumn{7}{|l|}{ Morning period (06:00-12:00 hours) } \\
\hline Average glucose concentration (mmol/l) & & & & $<0.001^{*}, \dagger$ & $0.026^{\S}$ & 0.239 \\
\hline IGT & $8.1 \pm 0.5$ & $7.5 \pm 0.4$ & $7.0 \pm 0.4$ & & & \\
\hline OGLM & $10.2 \pm 0.7$ & $8.6 \pm 0.4$ & $9.4 \pm 0.5$ & & & \\
\hline INS & $9.5 \pm 0.6$ & $8.4 \pm 0.5$ & $8.5 \pm 0.8$ & & & \\
\hline Hyperglycaemia (h:min) & & & & $<0.001^{*}, \dagger$ & $0.005^{\S}$ & 0.186 \\
\hline IGT & $0: 52 \pm 0: 22$ & $0: 37 \pm 0: 16$ & $0: 25 \pm 0: 13$ & & & \\
\hline OGLM & $3: 01 \pm 0: 30$ & $1: 41 \pm 0: 20$ & $2: 11 \pm 0: 20$ & & & \\
\hline INS & $2: 23 \pm 0: 27$ & $1: 19 \pm 0: 27$ & $1: 35 \pm 0: 30$ & & & \\
\hline Hypoglycaemia (h:min) & & & & 0.850 & 0.288 & 0.869 \\
\hline IGT & $0: 06 \pm 0: 05$ & $0: 02 \pm 0: 02$ & $0: 06 \pm 0: 05$ & & & \\
\hline OGLM & $0: 04 \pm 0: 04$ & $0: 07 \pm 0: 07$ & $0: 01 \pm 0: 01$ & & & \\
\hline INS & $0: 12 \pm 0: 09$ & $0: 12 \pm 0: 06$ & $0: 08 \pm 0: 07$ & & & \\
\hline
\end{tabular}

Data are expressed as means \pm SEM

Significance values obtained from post hoc analyses: difference resistance vs control, ${ }^{*} p<0.05$; difference endurance vs control, ${ }^{\dagger} p<0.05$; difference endurance vs resistance, ${ }^{\ddagger} p<0.05$; difference OGLM vs IGT, ${ }^{\S} p<0.05$; difference INS vs IGT, ${ }^{\natural} p<0.05$; difference INS vs OGLM, $* * p<0.05$

\section{Discussion}

The present study shows that hyperglycaemia is highly prevalent throughout the day in individuals with IGT, and insulin-treated and non-insulin-treated type 2 diabetic patients. A single session of endurance- or resistance-type exercise can substantially lower the prevalence of hyperglycaemia throughout the subsequent day.

In agreement with previous results $[2,3]$, we show that postprandial hyperglycaemia (defined as glucose levels $>10 \mathrm{mmol} / \mathrm{l}$ ) remains an underestimated problem in type 2 diabetes. Despite the continued use of bloodglucose-lowering medication and the provision of a healthy, well-balanced diet, the insulin- and non-insulintreated type 2 diabetic patients were in a hyperglycaemic state for $34 \pm 7 \%$ and $38 \pm 7 \%$ of the $24 \mathrm{~h}$ assessment period (Fig. 2). In addition, this study is the first to assess glycaemic profiles in prediabetic individuals with IGT. With hyperglycaemia being present for $9 \pm 3 \%$ of the day, the IGT individuals experienced substantially less hyperglycaemia throughout the day when compared with the diabetic patients consuming the same standardised diet
(Fig. 2). Nonetheless, $9 \pm 3 \%$ of hyperglycaemia is still threefold higher than the hyperglycaemic episodes that were previously recorded in overweight, normoglycaemic men using a comparable standardised diet [3, 22]. Evidently, there is need for effective treatment strategies in both prediabetic individuals, type 2 diabetic patients using OGLMs, and long-standing insulin-treated type 2 diabetic patients to reduce the prevalence of hyperglycaemia, and thereby improve daily glycaemic control.

The effects of long-term exercise training on glycaemic control (i.e. $\mathrm{HbA}_{1 \mathrm{c}}$ ) have been well established [5], and can be largely ascribed to an improved insulin sensitivity. Nevertheless, the effects of exercise training on insulin sensitivity may be lost entirely 6-14 days after cessation of training [23]. Therefore, improvements in glycaemic control following exercise training can be largely attributed to the cumulative effects of transient improvements in glucose tolerance following each successive bout of exercise, rather than to the structural adaptive response to prolonged exercise training $[6,7,24]$. As a consequence, information on the acute glucoregulatory effects of exercise can be used to optimise the application of exercise as an effective 
strategy to improve glycaemic control in type 2 diabetic patients. We have recently shown that a single bout of continuous endurance-type exercise strongly reduces the prevalence of hyperglycaemia and lowers blood glucose concentrations throughout the subsequent $24 \mathrm{~h}$ in type 2 diabetic patients [9]. However, as recognised by the current ADA/ACSM position statement [13], the acute effects of resistance-type exercise on glycaemic control are less evident. Although single bouts of endurance- $[25,26]$ and resistance-type exercise [17, 27] have been reported to improve insulin sensitivity for at least $24 \mathrm{~h}$, no studies have directly assessed the impact of resistance-type exercise on subsequent glycaemic control. In the present study, continuous glucose monitoring was applied under standardised dietary, but otherwise free living, conditions to assess the effects of both resistance- and endurance-type exercise on glycaemic control throughout the subsequent day. A single bout of resistancetype exercise reduced the prevalence of hyperglycaemia by as much as $35 \pm 7 \%$ during the $24 \mathrm{~h}$ post-exercise period when compared with the control (no exercise) experiment. A similar $33 \pm 11 \%$ reduction in the prevalence of hyperglycaemia was observed following a corresponding $45 \mathrm{~min}$ bout of endurance-type exercise (Fig. 2). Previously, the benefits of resistance-type exercise training on glycaemic control have often been ascribed to an increase in muscle mass over time and concomitant expansion of glucose disposal capacity [12]. However, the present study clearly shows that a single bout of resistance-type exercise improves glycaemic control for up to $24 \mathrm{~h}$ following exercise, without changes in muscle mass. These acute improvements in glycaemic control following resistance-type exercise might be explained by direct improvements in insulin-dependent [17, 28] and insulin-independent [29] glucose uptake, similar to the effects generally observed following endurance-type exercise $[6,30]$. Furthermore, as medication was kept stable, diets were standardised, and habitual physical activity was monitored, the effects of both types of exercise occurred independent from changes in medication, diet and habitual physical activity. It should be noted, however, that the observed effects of both types of exercise are only valid for the exercise intensities applied in the present study. The moderate-to-high intensity workload applied in both exercise treatments was perceived as strenuous but feasible for all participants. Although endurance-type exercise has been reported to be also effective at lower intensities [9], the acute glucoregulatory effects of resistance-type exercise at lower exercise intensities remain to be established.

In the present study, we assessed the impact of both resistance- and endurance-type exercise on subsequent glycaemic control in three diabetic subpopulations: prediabetic IGT individuals; type 2 diabetic patients treated with OGLM; and long-standing type 2 diabetic patients using insulin treatment. Overall, exercise lowered average $24 \mathrm{~h}$ blood glucose concentrations by $\sim 0.8 \mathrm{mmol} / \mathrm{l}$, while the prevalence of hyperglycaemia was reduced by $\sim 34 \%$. Both resistance- and endurance-type exercise effectively reduced the prevalence of hyperglycaemia and, as such, improved glycaemic control in all type 2 diabetic subpopulations. Interestingly, the blood-glucose-lowering effects of exercise in the type 2 diabetic patients were observed on top of pharmacological treatment. In the IGT individuals, exercise reduced the prevalence of hyperglycaemia, approaching a level previously observed in normally glucose tolerant individuals [3]. Whether the high prevalence of hyperglycaemia as previously reported in type 1 diabetic patients [31] can also be effectively reduced by both resistance- and endurance-type exercise remains to be established.

In addition to hyperglycaemia, we also assessed the prevalence of hypoglycaemia in the diabetic subpopulations. Hypoglycaemia is less frequently experienced by type 2 diabetic patients when compared with type 1 diabetic patients [32]. However, patients with advanced type 2 diabetes are also at an increased risk of hypoglycaemic episodes [33]. In agreement, the overall prevalence of hypoglycaemia (defined as blood glucose concentrations $<3.9 \mathrm{mmol} / \mathrm{l}$ ) in the present study tended to be higher in the long-standing insulin-treated type 2 diabetic patients when compared with the IGT and OGLM groups (between-group effect $p=0.062$ ), but the prevalence was still of minor relevance (between 30 and $40 \mathrm{~min}$ per day). Though exercise can cause temporary hypoglycaemia [32], we failed to observe any impact of resistance- or endurance-type exercise on the daily prevalence of hypoglycaemia (main effect $p=0.602$ ). This is not surprising, as we ensured that exercise was performed in the postprandial state, with meals and snacks being provided at regular intervals throughout the day. Such a balanced interplay between exercise and nutrition is generally effective for preventing exercise-induced hypoglycaemia.

In conclusion, a single session of resistance- or endurancetype exercise substantially reduces the prevalence of hyperglycaemia and improves glycaemic control during the subsequent $24 \mathrm{~h}$ period in individuals with IGT, and in insulin-treated and non-insulin-treated type 2 diabetic patients. Given the equal impact of both types of exercise on daily glycaemic control, endurance-type exercise sessions can be exchanged for resistance-type exercise sessions without abating the positive impact of exercise on glycaemic control. Consequently, a more personalised exercise prescription, tailored to the needs and capabilities of the individual type 2 diabetic patient, is feasible.

Acknowledgements The described work was supported by a grant from the Netherlands Organization for Health Research and Development (ZonMw, the Netherlands).

Duality of interest None of the authors had any personal and/or financial conflict of interest with regard to this study. 
Contribution statement JWvD designed the study, collected and analysed data, and drafted the manuscript. RJFM designed the study and edited the manuscript. KT and AGB collected the data and edited the manuscript. CDAS and FH edited the manuscript. $\mathrm{LJCvL}$ designed the study, analysed data and drafted the manuscript. All authors were involved in the interpretation of data and contributed to the manuscript for important intellectual content. All authors approved the final version to be published.

Open Access This article is distributed under the terms of the Creative Commons Attribution Noncommercial License which permits any noncommercial use, distribution, and reproduction in any medium, provided the original author(s) and source are credited.

\section{References}

1. Ceriello A (2005) Postprandial hyperglycemia and diabetes complications: is it time to treat? Diabetes $54: 1-7$

2. Praet SF, Manders RJ, Meex RC et al (2006) Glycaemic instability is an underestimated problem in type II diabetes. Clin Sci (Lond) 111:119-126

3. van Dijk JW, Manders RJ, Hartgens F, Stehouwer CD, Praet SF, van Loon LJ (2011) Postprandial hyperglycemia is highly prevalent throughout the day in type 2 diabetes patients. Diabetes Res Clin Pract 93:31-37

4. Snowling NJ, Hopkins WG (2006) Effects of different modes of exercise training on glucose control and risk factors for complications in type 2 diabetic patients: a meta-analysis. Diabetes Care 29:2518-2527

5. Boule NG, Haddad E, Kenny GP, Wells GA, Sigal RJ (2001) Effects of exercise on glycemic control and body mass in type 2 diabetes mellitus: a meta-analysis of controlled clinical trials. JAMA 286:1218-1227

6. Goodyear LJ, Kahn BB (1998) Exercise, glucose transport, and insulin sensitivity. Annu Rev Med 49:235-261

7. Praet SF, van Loon LJ (2007) Optimizing the therapeutic benefits of exercise in type 2 diabetes. J Appl Physiol 103:1113-1120

8. Henriksen EJ (2002) Invited review: effects of acute exercise and exercise training on insulin resistance. J Appl Physiol 93:788-796

9. Manders RJ, van Dijk JW, van Loon LJ (2010) Low-intensity exercise reduces the prevalence of hyperglycemia in type 2 diabetes. Med Sci Sports Exerc 42:219-225

10. Hansen D, Dendale P, Jonkers RA et al (2009) Continuous low- to moderate-intensity exercise training is as effective as moderate- to high-intensity exercise training at lowering blood $\mathrm{HbA}(1 \mathrm{c})$ in obese type 2 diabetes patients. Diabetologia 52:1789-1797

11. Ross R, Dagnone D, Jones PJ et al (2000) Reduction in obesity and related comorbid conditions after diet-induced weight loss or exercise-induced weight loss in men. A randomized, controlled trial. Ann Intern Med 133:92-103

12. Eves ND, Plotnikoff RC (2006) Resistance training and type 2 diabetes: considerations for implementation at the population level. Diabetes Care 29:1933-1941

13. Colberg SR, Sigal RJ, Fernhall B et al (2010) Exercise and type 2 diabetes: the American College of Sports Medicine and the American Diabetes Association: joint position statement. Diabetes Care 33:e147-e167

14. Willey KA, Singh MA (2003) Battling insulin resistance in elderly obese people with type 2 diabetes: bring on the heavy weights. Diabetes Care 26:1580-1588

15. Park SW, Goodpaster BH, Strotmeyer ES et al (2006) Decreased muscle strength and quality in older adults with type 2 diabetes: the health, aging, and body composition study. Diabetes 55:18131818

16. ADA (2010) Diagnosis and classification of diabetes mellitus. Diabetes Care 33(Suppl 1):S62-S69

17. Koopman R, Manders RJ, Zorenc AH et al (2005) A single session of resistance exercise enhances insulin sensitivity for at least $24 \mathrm{~h}$ in healthy men. Eur J Appl Physiol 94:180-187

18. Mari A, Pacini G, Murphy E, Ludvik B, Nolan JJ (2001) A model-based method for assessing insulin sensitivity from the oral glucose tolerance test. Diabetes Care 24:539-548

19. Castaneda C, Layne JE, Munoz-Orians L et al (2002) A randomized controlled trial of resistance exercise training to improve glycemic control in older adults with type 2 diabetes. Diabetes Care 25:2335-2341

20. Bonomi AG, Plasqui G, Goris AH, Westerterp KR (2010) Estimation of free-living energy expenditure using a novel activity monitor designed to minimize obtrusiveness. Obesity (Silver Spring) 18:1845-1851

21. Bantle JP, Wylie-Rosett J, Albright AL et al (2008) Nutrition recommendations and interventions for diabetes: a position statement of the American Diabetes Association. Diabetes Care 31(Suppl 1):S61-S78

22. Manders RJ, Pennings B, Beckers CP, Aipassa TI, van Loon LJ (2009) Prevalence of daily hyperglycemia in obese type 2 diabetic men compared with that in lean and obese normoglycemic men: effect of consumption of a sucrose-containing beverage. Am J Clin Nutr 90:511-518

23. Dela F, Larsen JJ, Mikines KJ, Ploug T, Petersen LN, Galbo H (1995) Insulin-stimulated muscle glucose clearance in patients with NIDDM. Effects of one-legged physical training. Diabetes 44:1010-1020

24. Schneider SH, Amorosa LF, Khachadurian AK, Ruderman NB (1984) Studies on the mechanism of improved glucose control during regular exercise in type 2 (non-insulin-dependent) diabetes. Diabetologia 26:355-360

25. Perseghin G, Price TB, Petersen KF et al (1996) Increased glucose transport-phosphorylation and muscle glycogen synthesis after exercise training in insulin-resistant subjects. $\mathrm{N}$ Engl $\mathrm{J}$ Med 335:1357-1362

26. Mikines KJ, Sonne B, Farrell PA, Tronier B, Galbo H (1988) Effect of physical exercise on sensitivity and responsiveness to insulin in humans. Am J Physiol 254:E248-E259

27. Fenicchia LM, Kanaley JA, Azevedo JL Jr et al (2004) Influence of resistance exercise training on glucose control in women with type 2 diabetes. Metabolism 53:284-289

28. Holten MK, Zacho M, Gaster M, Juel C, Wojtaszewski JF, Dela F (2004) Strength training increases insulin-mediated glucose uptake, GLUT4 content, and insulin signaling in skeletal muscle in patients with type 2 diabetes. Diabetes 53:294 305

29. Dreyer HC, Fujita S, Cadenas JG, Chinkes DL, Volpi E, Rasmussen BB (2006) Resistance exercise increases AMPK activity and reduces 4E-BP1 phosphorylation and protein synthesis in human skeletal muscle. J Physiol 576:613-624

30. Jessen N, Goodyear LJ (2005) Contraction signaling to glucose transport in skeletal muscle. J Appl Physiol 99:330-337

31. Bode BW, Schwartz S, Stubbs HA, Block JE (2005) Glycemic characteristics in continuously monitored patients with type 1 and type 2 diabetes: normative values. Diabetes Care 28:23612366

32. Cryer PE (2004) Diverse causes of hypoglycemia-associated autonomic failure in diabetes. N Engl J Med 350:2272-2279

33. Segel SA, Paramore DS, Cryer PE (2002) Hypoglycemiaassociated autonomic failure in advanced type 2 diabetes. Diabetes 51:724-733 